\title{
Chaos in a System with an Absolute Nonlinearity and Chaos Synchronization
}

\author{
Victor Kamdoum Tamba, ${ }^{1}$ Karthikeyan Rajagopal $\mathbb{D},{ }^{2}$ \\ Viet-Thanh Pham $(1),{ }^{3}$ and Duy Vo Hoang ${ }^{3}$ \\ ${ }^{1}$ Department of Telecommunication and Network Engineering, IUT-Fotso Victor of Bandjoun, University of Dschang, \\ P.O. Box 134, Bandjoun, Cameroon \\ ${ }^{2}$ Department of Electrical and Communication Engineering, The PNG University of Technology, Lae, Morobe, Papua New Guinea \\ ${ }^{3}$ Modeling Evolutionary Algorithms Simulation and Artificial Intelligent, Faculty of Electrical \& Electronics Engineering, \\ Ton Duc Thang University, Ho Chi Minh City, Vietnam
}

Correspondence should be addressed to Viet-Thanh Pham; phamvietthanh@tdt.edu.vn

Received 21 October 2017; Revised 21 December 2017; Accepted 2 January 2018; Published 30 January 2018

Academic Editor: Zhi-Yuan Sun

Copyright ( 2018 Victor Kamdoum Tamba et al. This is an open access article distributed under the Creative Commons Attribution License, which permits unrestricted use, distribution, and reproduction in any medium, provided the original work is properly cited.

A system with an absolute nonlinearity is studied in this work. It is noted that the system is chaotic and has an adjustable amplitude variable, which is suitable for practical uses. Circuit design of such a system has been realized without any multiplier and experimental measurements have been reported. In addition, an adaptive control has been applied to get the synchronization of the system.

\section{Introduction}

Although chaos in dynamic systems has been investigated for many years [1-4], new systems with chaos still attract the attention of numerous researches [5-11]. Finding new chaotic systems and investigating chaos control and chaos synchronization methodologies are attractive topics [12-15] due to the applications of chaos in various areas such as waveforms of chaotic radar [16], image encryption [17], secure image transmission [18], video encryption design [19], and S-box construction [20].

Previous studies suggest that absolute function is effective to design chaotic systems $[21,22]$. It is worth noting that an absolute term is not a quadratic nonlinearity and can be implemented with diodes and operational amplifiers [22]. By using an absolute term, one of the most elementary chaotic systems was introduced by Linz and Sprott [21]. Such a system was also realized by a circuit [22]. Jerk systems with absolute nonlinearities were presented in [23]. Authors investigated the synchronization of a chaotic system, which includes only four terms and an absolute-value nonlinearity [24]. In addition, absolute-value term was explored to propose a hyperchaotic circuit without any multiplier [25]. Huang and Liu introduced a fractional-order chaotic system with the presence of an absolute term [26]. Bao et al. designed a memristor-based system with four line equilibria by implementing three absolute terms [27]. It is interesting that adjustable amplitude of chaotic attractor was obtained with absolute terms [28].

The aim of this work is to study a simple system with chaos. There is only one nonlinear term, an absolute nonlinearity, in such system. It is noted that the system exhibits variable chaotic attractors, which have been rarely investigated in Sprott's systems with absolute-value nonlinearity and six terms. Dynamics, circuit, and synchronization of such a system with an absolute nonlinearity are presented in the next sections.

\section{The System with an Absolute Term and Its Dynamics}

Absolute function has been applied to construct different systems with chaotic behavior $[27,28]$. In this work, by 


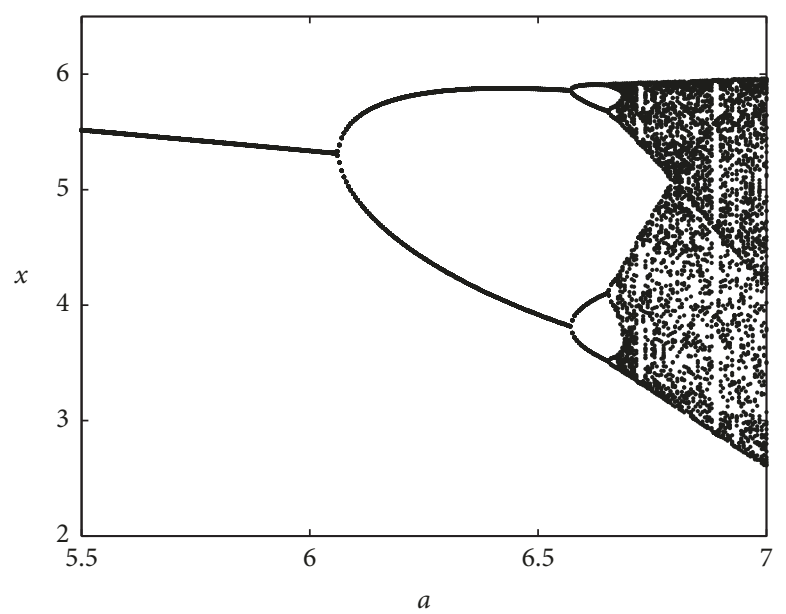

Figure 1: Presentation of the bifurcation diagram for $a \in[5.5,7]$, while $b=4$ and $c=1$.

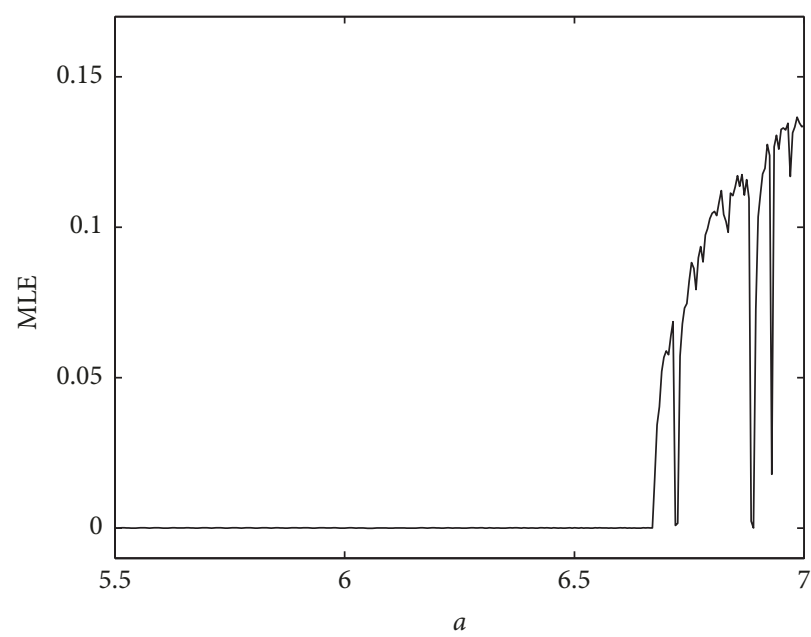

FIgURE 2: Presentation of maximum Lyapunov exponents for $a \in[5.5,7]$, while $b=4$ and $c=1$.

using an absolute nonlinearity, we study a six-term system described by

$$
\begin{aligned}
& \dot{x}=a|y|+b z, \\
& \dot{y}=1+z, \\
& \dot{z}=-c x-z .
\end{aligned}
$$

System (1) has three positive parameters $(a, b, c>0)$. We have found that system (1) displays different behavior when varying the parameter $a$.

We have changed the parameter $a$ for plotting the bifurcation diagram and the maximum Lyapunov exponents (presented in Figures 1 and 2). As shown in Figures 1 and 2, system (1) is periodic for $a<6.67$. From Figures 1 and 2, we also observe a period doubling route to chaos, which is illustrated further in Figure 3. For $a>6.67$, chaotic dynamics can be seen. For $a=6.8, b=4$, and $c=1$, chaos in system (1) is presented in Figure 4. Chaos in this case is verified by the Lyapunov exponents of the system $L_{1}=0.1046>0, L_{2}=0$, and $L_{3}=-1.1048$.
Interestingly, we can change the amplitude of the variable $x$ easily by adding a control parameter $\left(k_{x}\right)$ into system (1):

$$
\begin{aligned}
& \dot{x}=a|y|+b z, \\
& \dot{y}=1+z, \\
& \dot{z}=-c x-z+k_{x} .
\end{aligned}
$$

As shown in Figure 5, chaotic attractors are adjusted by using the control parameter $k_{x}$. When increasing $k_{x}$, the average value of the variable $x$ is increased (see Figure 6).

Moreover, the amplitudes of three variables $(x, y, z)$ are changed simultaneously by introducing a control parameter $\left(k_{x y z}\right)$ into system (1) as follows:

$$
\begin{aligned}
& \dot{x}=a|y|+b z, \\
& \dot{y}=k_{x y z}+z, \\
& \dot{z}=-c x-z .
\end{aligned}
$$




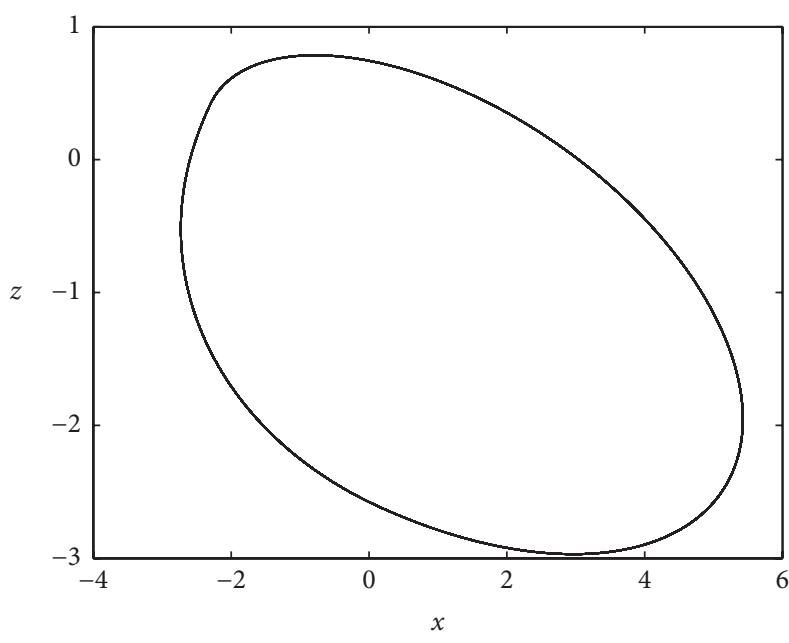

(a)

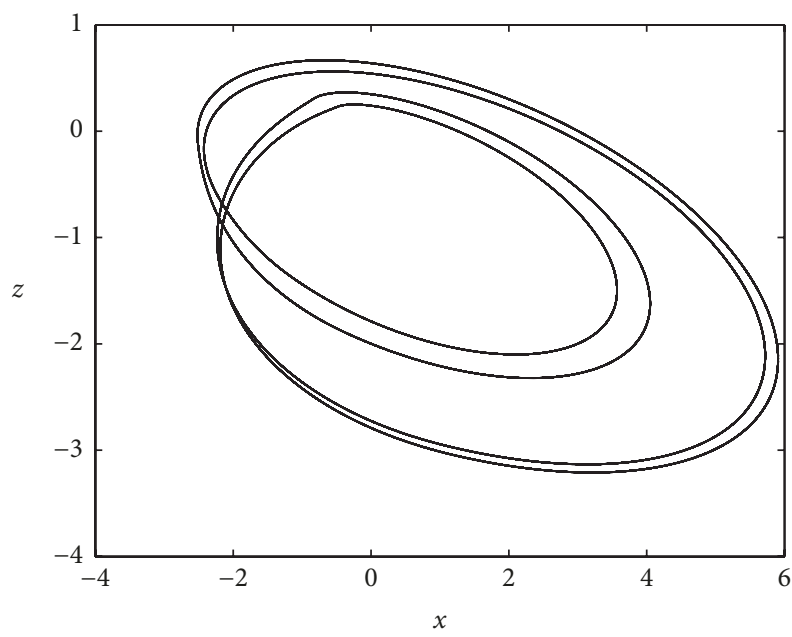

(c)

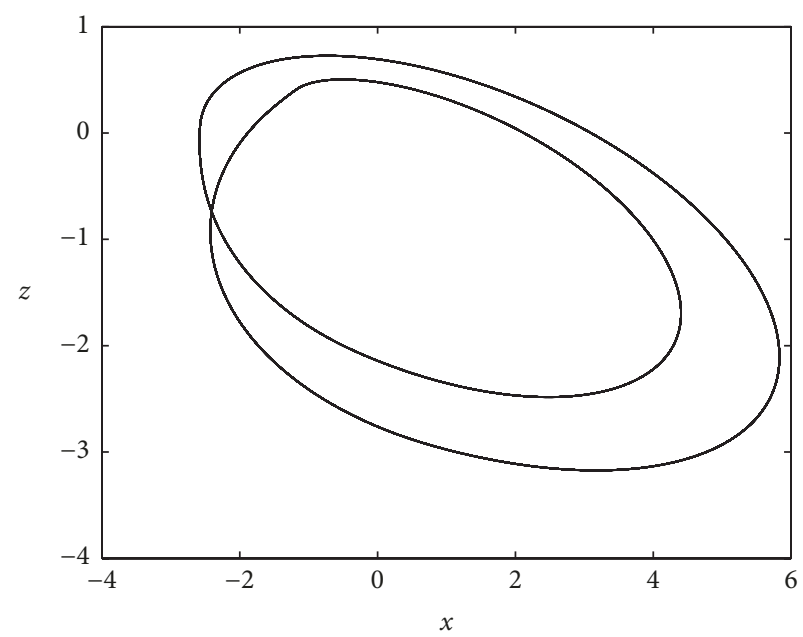

(b)

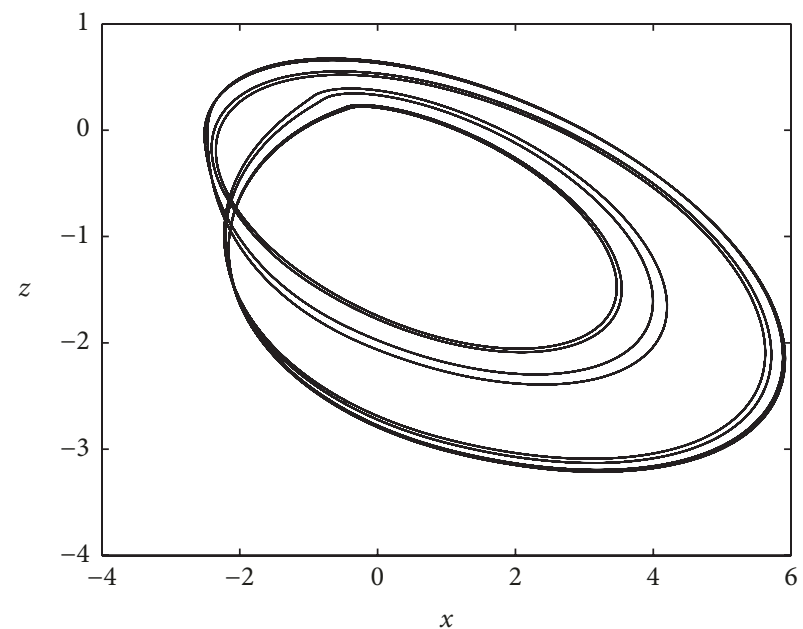

(d)

FIGURE 3: Different periodical dynamics observed in $x$ - $z$ plane for $b=4$ and $c=1$; initial conditions $(x(0), y(0), z(0))=(0,0,0)$ when $($ a) $a=5.75$, (b) $a=6.25$, (c) $a=6.625$, and (d) $a=6.665$.

As illustrated in Figure 7, chaotic attractors are reduced and enlarged when varying the control parameter $k_{x y z}$. It is worth noting that Sprott has discovered various systems with absolute-value nonlinearity and six terms [3]. However, there are few systems displaying controllable chaotic attractors, which have received significant attention recently [29-31].

\section{Circuit Design for the System}

The numerical approach is vital for investigation of the dynamics of theoretical chaotic models [32-35]. By using this method, the dynamical behaviors of such models can be characterized in terms of their parameters. However, to explore their feasibilities, the electronic circuit implementation of these theoretical models is needed [36-39]. Moreover, the physical realization of theoretical chaotic models is relevant in many engineering applications [40-42]. In this section, we design and implement an electronic circuit to illustrate the feasibility of system (1). The electronic circuit diagram for system (1) is depicted in Figure 8.

The circuit diagram of Figure 8 consists of operational amplifiers associated with resistors and capacitors exploited to implement the basic operations such as integration, addition, and subtraction. The nonlinear term of the model is implemented by absolute-value circuit of Figure 8(b). The bias is provided by a 15 Volts DC symmetry source. By applying Kirchhoff's laws into the circuit of Figure 8, we obtain the following state equations:

$$
\begin{aligned}
& \frac{d V_{x}}{d t}=\frac{\left|V_{y}\right|}{R_{a} C}+\frac{V_{z}}{R_{b} C} \\
& \frac{d V_{y}}{d t}=\frac{V_{D C}}{R C}+\frac{V_{z}}{R C} \\
& \frac{d V_{z}}{d t}=-\frac{V_{x}}{R_{c} C}-\frac{V_{z}}{R C},
\end{aligned}
$$




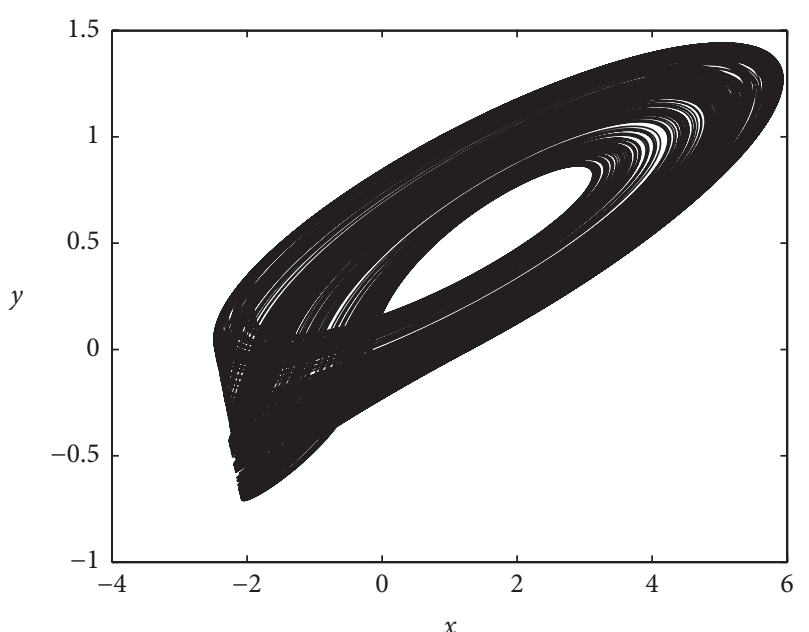

(a)

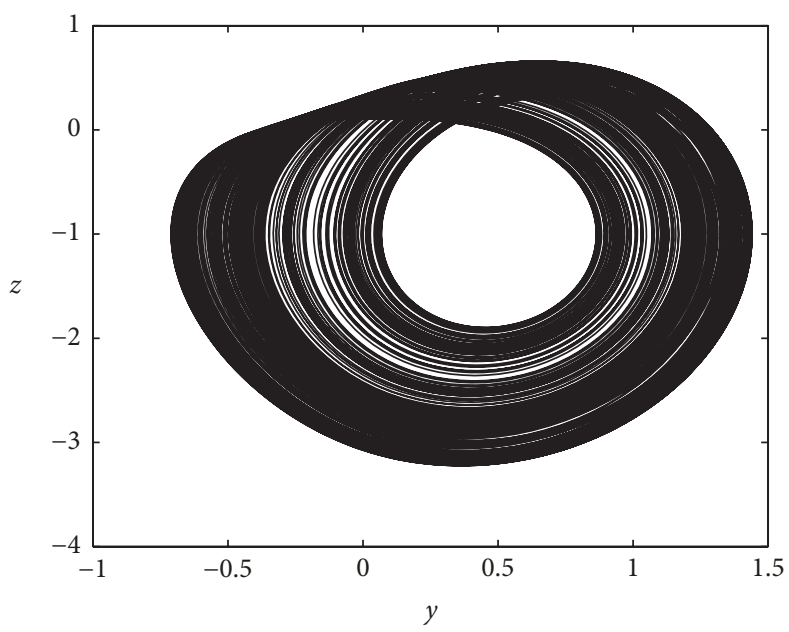

(c)

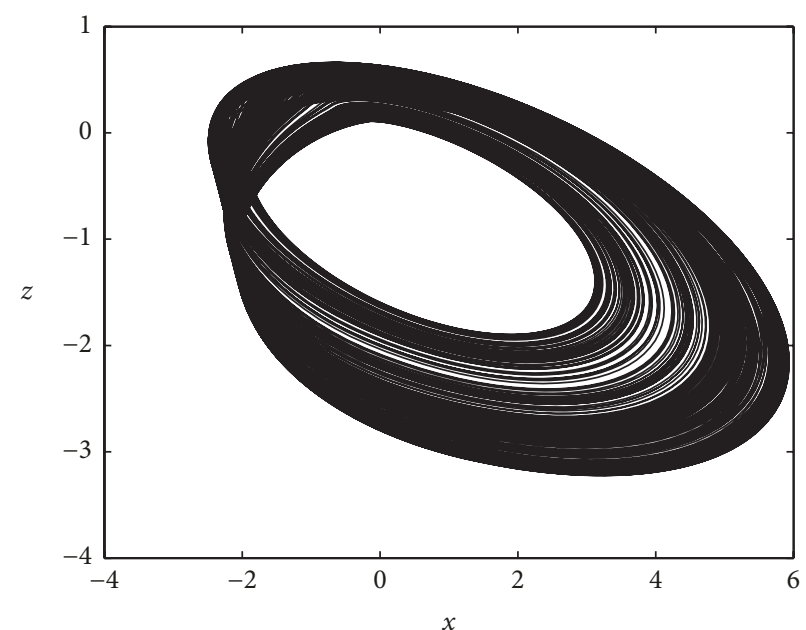

(b)

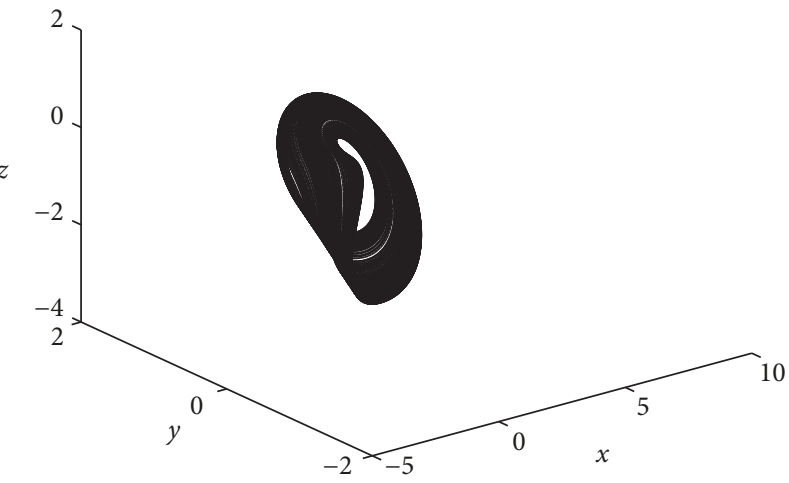

(d)

Figure 4: Phase portrait observed in (a) $x-y$ plane, (b) $x-z$ plane, (c) $y$ - $z$ plane, and (d) $x-y-z$ space for $a=6.8, b=4$, and $c=1$ and initial conditions $(x(0), y(0), z(0))=(0,0,0)$.

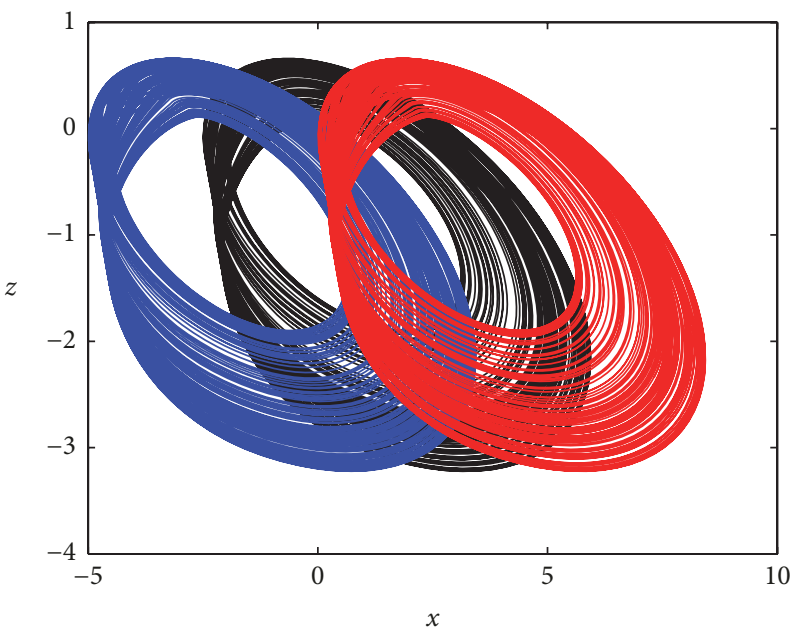

FIGURE 5: Variable chaotic attractor when varying the control parameter $k_{x}$ : black color for $k_{x}=0$, blue color for $k_{x}=-2$, and red color for $k_{x}=2$. 


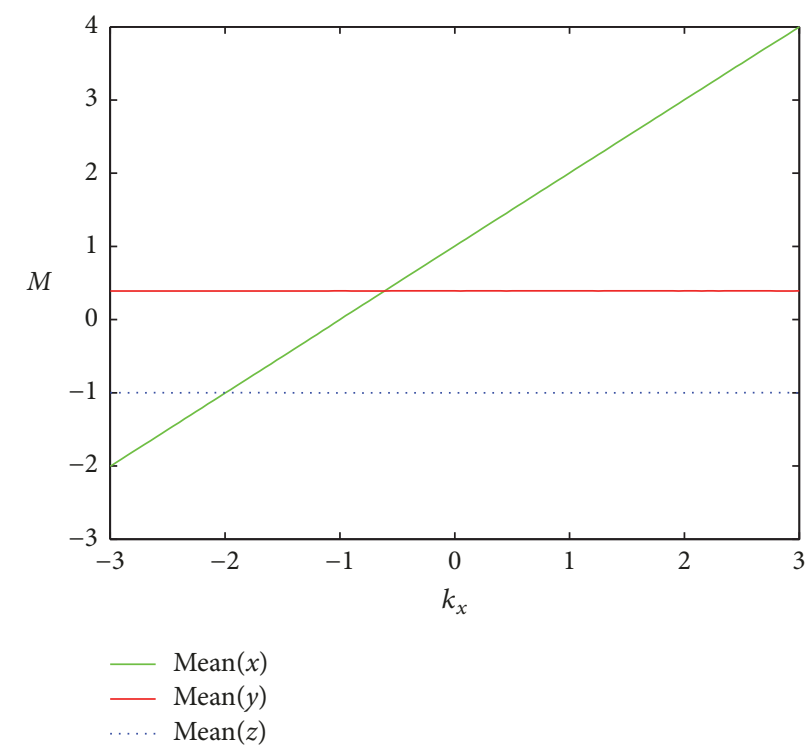

FIgURE 6: Average values of three variables $(x, y, z)$ for $k_{x} \in[-3,3]$.

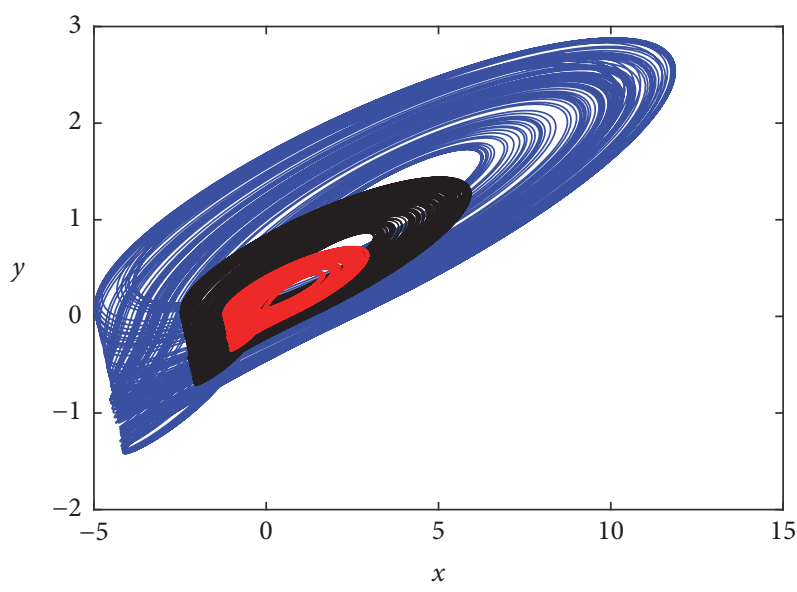

(a)

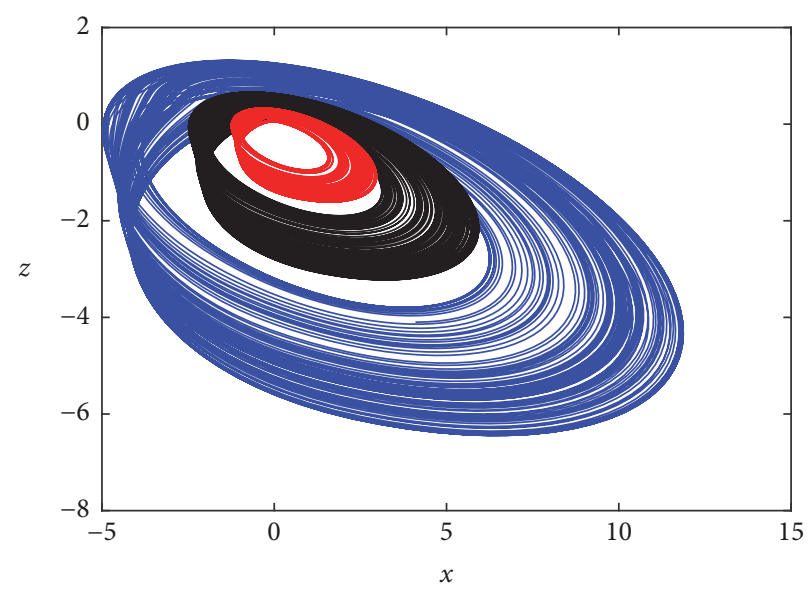

(b)

FIGURE 7: Controllable chaotic attractors in (a) $x-y$ plane and (b) $x-z$ plane when varying the control parameter $k_{x y z}$ : black color for $k_{x y z}=1$, blue color for $k_{x y z}=2$, and red color for $k_{x y z}=0.5$.

where $V_{x}, V_{y}$, and $V_{z}$ are the output voltages of the operational amplifiers OP_1, OP_2, and OP_3, respectively. In order to compare system (4) with theoretical model (1), the following settings of variables and parameters, $V_{x}=x \times 1 V, V_{y}=y \times 1 V$, $V_{z}=z \times 1 V, t=\tau R C, a=R / R_{a}, b=R / R_{b}$, and $c=R / R_{c}$, are adopted. With the following values of parameters, $a=6.8$, $b=4$, and $c=1$ (for which system (1) displays chaotic behavior), the values of circuit components are selected as follows: $C=10 \mathrm{nF}, R=10 \mathrm{k} \Omega, R_{a}=1.47 \mathrm{k} \Omega, R_{b}=2.5 \mathrm{k} \Omega$, and $R_{c}=10 \mathrm{k} \Omega$.

As shown in Figure 9, the circuit has been implemented and experimental measurements have been recorded. Details of the real circuit are presented in Figure 10. The experimental phase portraits of the circuit in $\left(V_{x}, V_{y}\right),\left(V_{x}, V_{z}\right)$, and $\left(V_{y}, V_{z}\right)$ planes obtained with an oscilloscope are shown in Figure 11.
From Figure 11, one can see that the experimental chaotic phase portraits agree with those obtained from the numerical simulations. This means that the proposed electronic circuit emulates well the dynamics of theoretical model (1).

\section{Synchronization for the System with Unknown Parameters}

It is well known that, in practical situations, some or all of the system parameters cannot be exactly known in advance. Also, most parameters values are characterized by uncertainties related to the modeling errors or experimental conditions (temperature, external electric and magnetic fields, etc.) that can destroy or even break the synchronization [43-45]. 


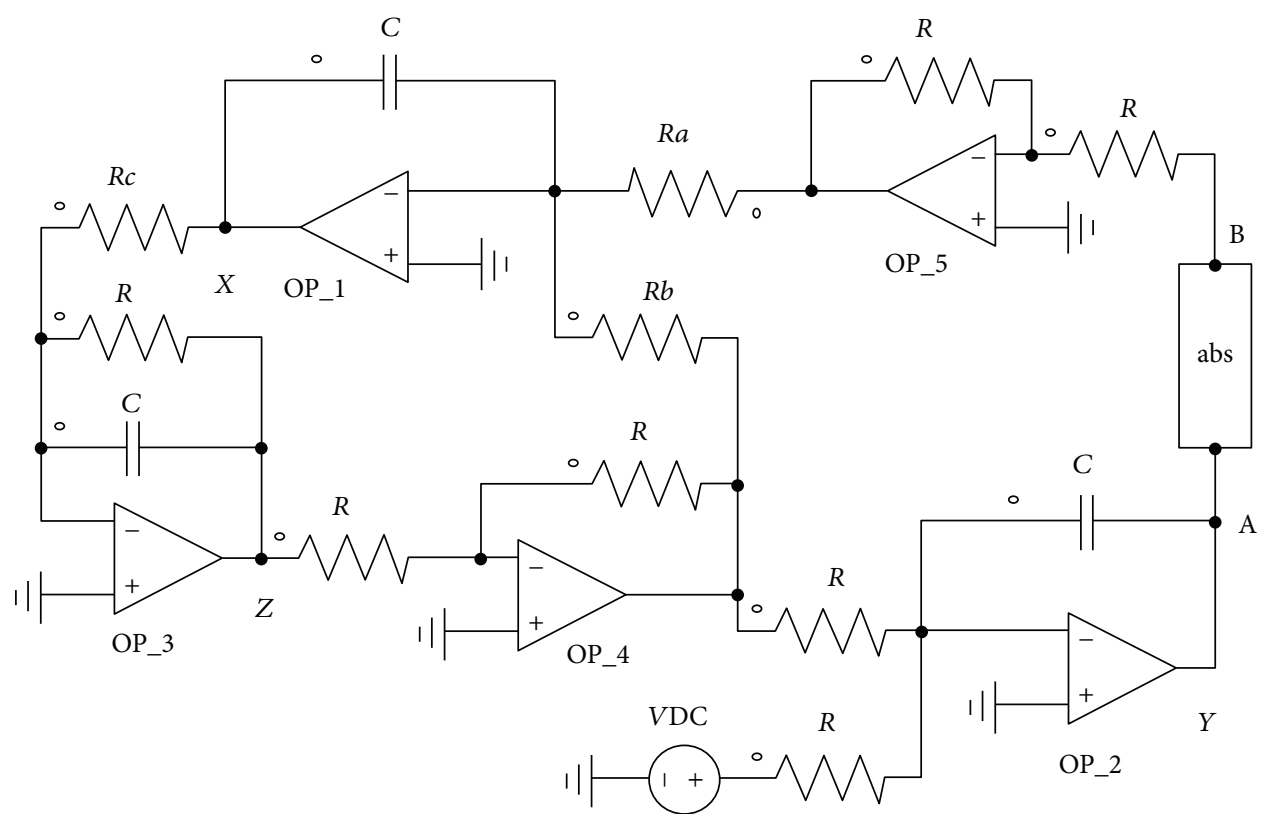

(a)

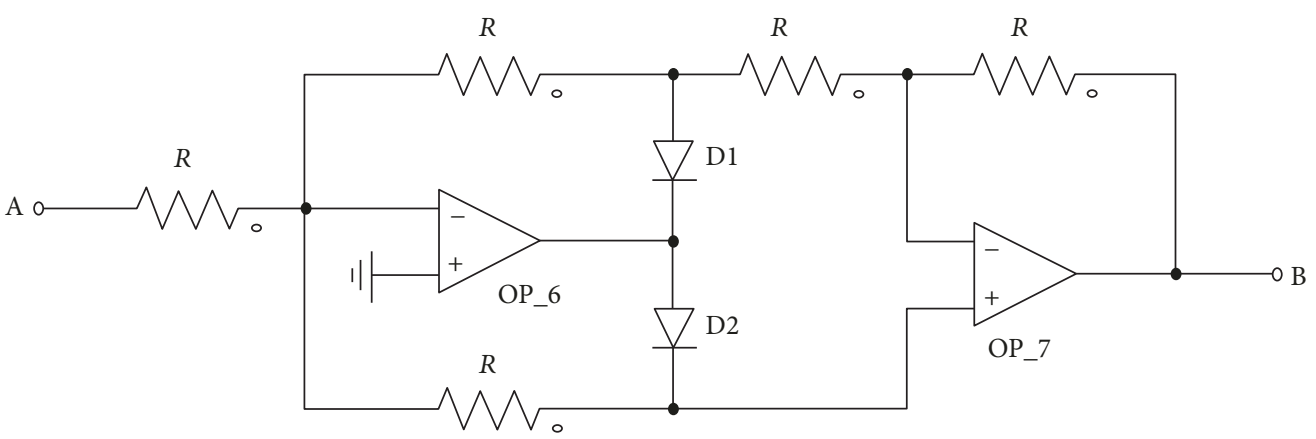

(b)

FIGURE 8: Electronic circuit design of system (1) (a) and the circuit realization of the absolute value function (b).

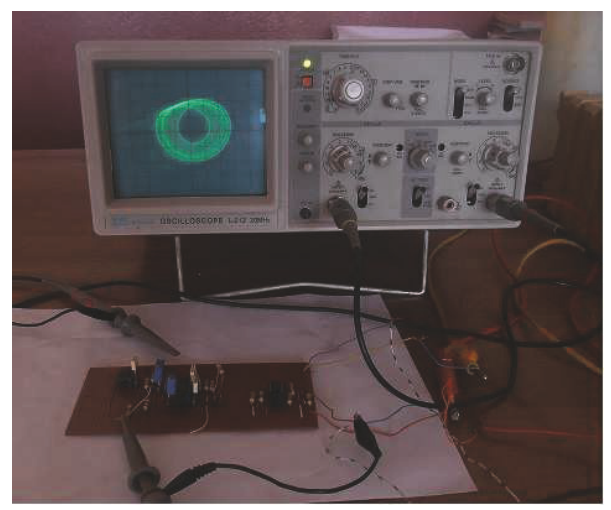

FIGURE 9: Implemented circuit was measured by using an oscilloscope.

Therefore, it is essential to consider the synchronization problem of chaotic systems in the presence of unknown system parameters. In this section, we design an adaptive control scheme [43] to synchronize two identical structures of system (1) with unknown parameters.
4.1. Design of the Slave System. We will assume that all the state variables and parameters of the master system (1) are accessible to measurements and those of slave system are unknown. Based on the concept of adaptive method, the following theorem is formulated. 


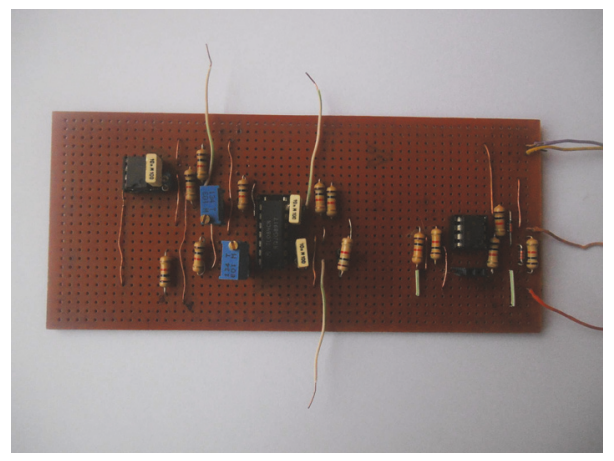

FIGURE 10: Real circuit implemented by using electronic components.

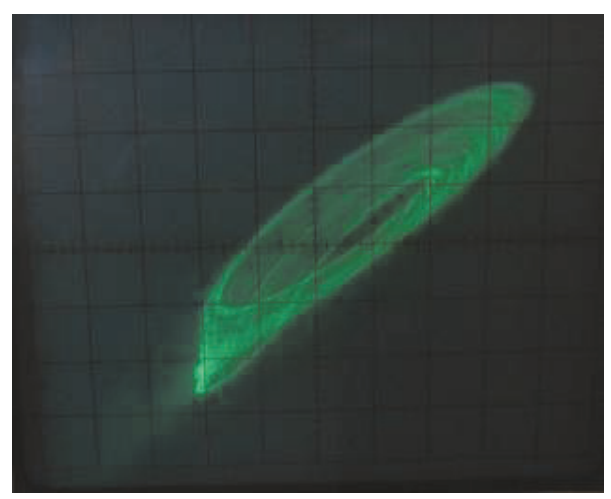

(a)

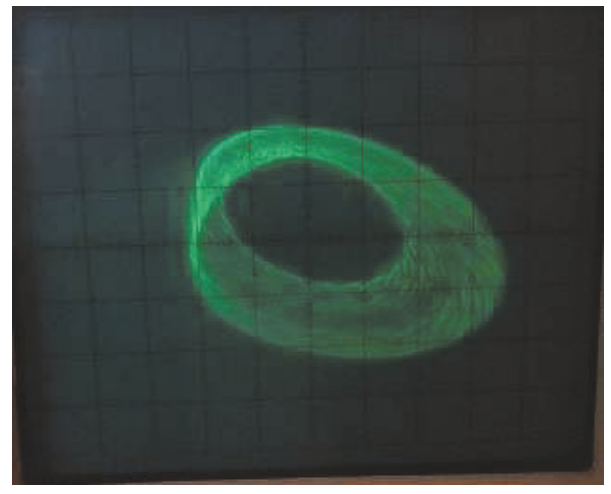

(b)

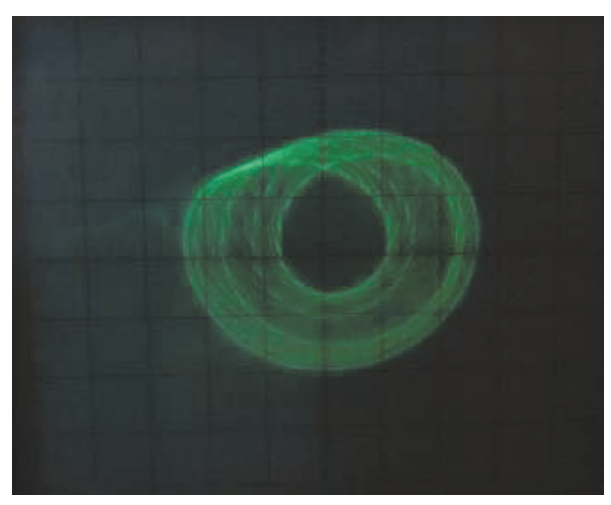

(c)

FigURE 11: Experimental phase portraits of the real circuit in (a) $\left(V_{x}, V_{y}\right)$ plane, (b) $\left(V_{x}, V_{z}\right)$ plane, and (c) $\left(V_{y}, V_{z}\right)$ plane with $R_{a}=1.47 \mathrm{k} \Omega$, $R_{b}=2.5 \mathrm{k} \Omega$, and $R_{c}=10 \mathrm{k} \Omega$. 
Theorem 1. Let system (1) be the master system rewritten in the following form:

$$
\dot{X}_{m}=f\left(X_{m}\right)+F\left(X_{m}\right) \theta
$$

where

$$
\begin{gathered}
X_{m}\left(x_{m}, y_{m}, z_{m}\right)^{T}, \\
f\left(X_{m}\right)=\left(0,1+z_{m},-z_{m}\right)^{T}, \\
F\left(X_{m}\right)=\left(\begin{array}{ccc}
\left|y_{m}\right| & z_{m} & 0 \\
0 & 0 & 0 \\
0 & 0 & -x_{m}
\end{array}\right), \\
\theta=(a, b, c)^{T}
\end{gathered}
$$

then the slave system

$$
\dot{X}_{s}=f\left(X_{s}\right)+F\left(X_{s}\right) \hat{\theta}(t)+u
$$

can synchronize with the master system (5), with the control function u designed as

$u$

$$
=-\left\{e+f\left(X_{s}\right)-f\left(X_{m}\right)+\left[F\left(X_{s}\right)-F\left(X_{m}\right)\right] \widehat{\theta}(t)\right\}
$$

and the update law of the estimations of the unknown parameters determined by

$$
\dot{\hat{\theta}}(t)=-F^{T}\left(X_{m}\right) e,
$$

where $=X_{s}-X_{m}$ is the error system and $\widehat{\theta}=(\widehat{a}, \widehat{b}, \widehat{c})^{T}$ are the estimations of the corresponding parameters of the slave system (7).

Proof. The error dynamical system can be expressed as

$$
\dot{e}=\dot{X}_{s}-\dot{X}_{m}=-e+F\left(X_{m}\right)(\widehat{\theta}(t)-\theta) .
$$

Choose the storage Lyapunov function as

$$
V(e, \theta(t))=\frac{1}{2} e^{T} e+\frac{1}{2}(\widehat{\theta}(t)-\theta)^{T}(\widehat{\theta}(t)-\theta) .
$$

Then, the time derivative of $V(e, \theta(t))$ along the trajectory is

$$
\begin{aligned}
\dot{V} & =\frac{1}{2}\left(\dot{e}^{T} e+e^{T} \dot{e}\right)+\frac{1}{2}\left\{(\dot{\hat{\theta}}(t))^{T}(\hat{\theta}(t)-\theta)\right. \\
& \left.+(\widehat{\theta}(t)-\theta)^{T} \dot{\hat{\theta}}(t)\right\}=\frac{1}{2}\left\{-e^{T} e\right. \\
& +(\hat{\theta}(t)-\theta)^{T} F^{T}\left(X_{m}\right) e-e^{T} e \\
& \left.+e^{T} F\left(X_{m}\right)(\widehat{\theta}(t)-\theta)\right\}+\frac{1}{2}\left\{(\dot{\hat{\theta}}(t))^{T}(\widehat{\theta}(t)-\theta)\right. \\
& \left.+(\hat{\theta}(t)-\theta)^{T} \dot{\hat{\theta}}(t)\right\}=-e^{T} e .
\end{aligned}
$$

So $\dot{V}$ is negative semidefinite, and since $V$ is positive definite, it follows that $e \in L_{\infty}$ and $\theta \in L_{\infty}$. Thus $\dot{e} \in L_{\infty}$, and, according to (10), it can be obtained that

$$
\begin{aligned}
\int_{0}^{t}\|e\|^{2} d t & =\int_{0}^{t} e^{T} e d t \leq-\frac{1}{l} \int_{0}^{t} \dot{V} d t \\
& =\frac{1}{l}[V(0)-V(t)] \leq \frac{1}{l} V(0) .
\end{aligned}
$$

Since $V(0) \leq \infty$ and $e \in L_{2}$, according to Barbalat's lemma, we have $\|e(t)\| \rightarrow 0$ as $t \rightarrow \infty$; that is, the error dynamical system (10) will be stabilized at the zero equilibrium asymptotically. Thus, according to the Lyapunov stability theorem, the adaptive synchronization with unknown parameters between the drive system (5) and the response system (7) is achieved under the controller defined in (8) and parameters update law determined by (9). This completes the proof.

4.2. Numerical Verifications. For numerical verification, the master system is defined as in (5) with parameters $a, b$, and $c$. According to Theorem 1, the slave system is described as follows:

$$
\begin{aligned}
& \dot{x}_{s}=\widehat{a}\left|y_{m}\right|+\widehat{b} z_{m}-\left(x_{s}-x_{m}\right), \\
& \dot{y}_{s}=1+z_{m}-\left(y_{s}-y_{m}\right), \\
& \dot{z}_{s}=-\widehat{c} x_{m}-z_{m}-\left(z_{s}-z_{m}\right),
\end{aligned}
$$

where

$$
\begin{aligned}
& \dot{\hat{a}}=-\left|y_{m}\right|\left(x_{s}-x_{m}\right), \\
& \dot{\hat{b}}=-z_{m}\left(y_{s}-y_{m}\right), \\
& \dot{\hat{c}}=x_{m}\left(z_{s}-z_{m}\right) .
\end{aligned}
$$

The numerical computations are obtained using the standard fourth-order Runge-Kutta integration algorithm with a time step $\Delta t=0.001$; initial conditions on parameters are being selected randomly as follows: $\widehat{a}(0)=1.20, \widehat{b}(0)=0.80$, and $\widehat{c}(0)=0.25$. The master system's parameters are chosen as $a=6.8, b=4$, and $c=1$ in order to ensure the chaotic behavior. The synchronization errors and the graph of parameters estimations are shown in Figures 12 and 13, respectively.

Numerical simulations (see Figures 12 and 13) show that the adaptive synchronization between master system (5) and slave system (7) with unknown parameters is achieved successfully and the error signals approach asymptotically zero. Obviously, these results may be exploited in engineering applications such as communication, image processing, physics, and mechatronics.

\section{Conclusions}

By using an absolute nonlinearity, we have introduced a six-term system with chaos. Dynamics of the system with 


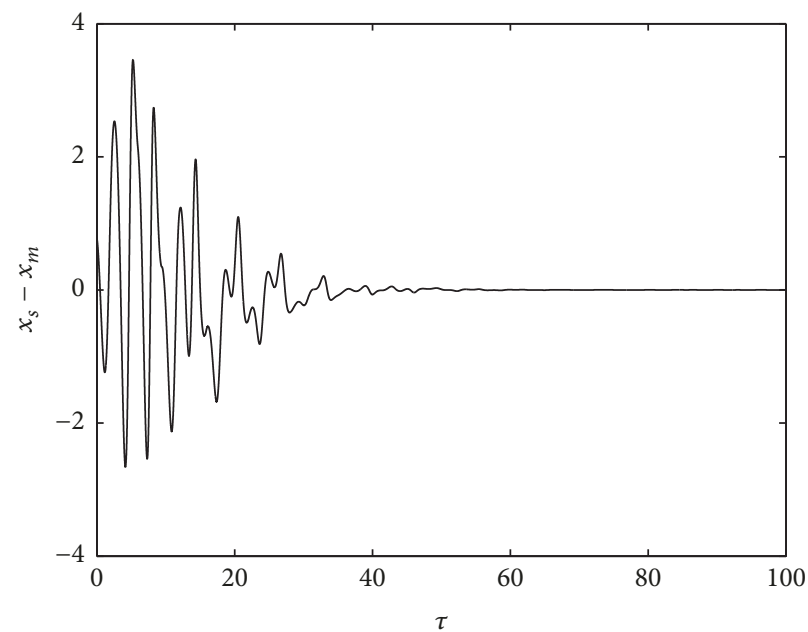

(a)

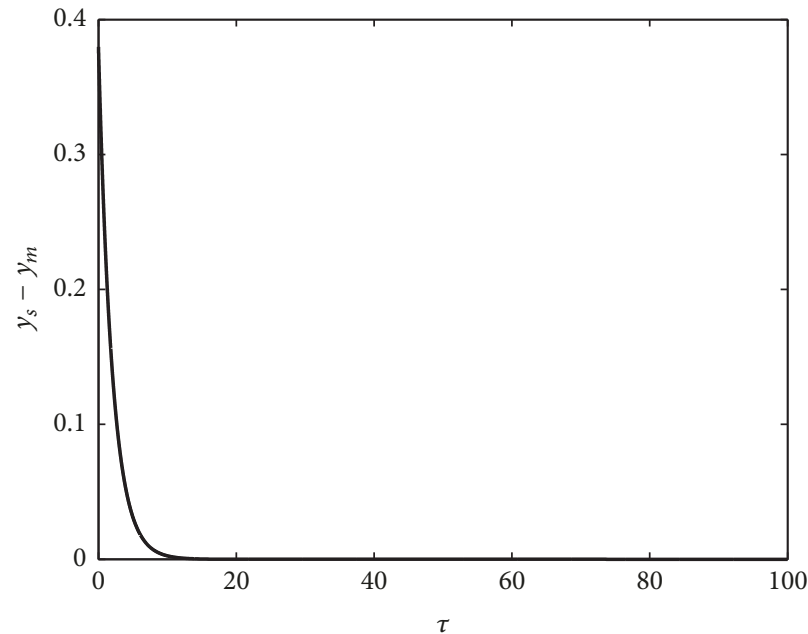

(b)

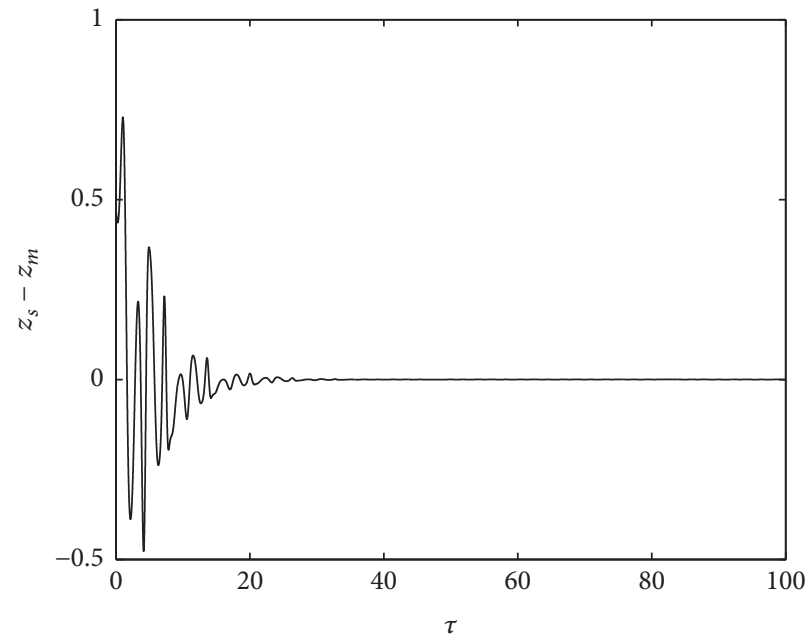

(c)

FIGURE 12: Error dynamics showing transition to synchronized states of the system and its observer. (a) $e_{x}=x_{s}-x_{m}$, (b) $e_{y}=y_{s}-y_{m}$, and (c) $e_{z}=z_{s}-z_{m}$. The initial conditions are chosen randomly as $x_{m}(0)=0.01, y_{m}(0)=0.02$, and $z_{m}(0)=0.03$ and $x_{s}(0)=0.8, y_{s}(0)=0.4$, and $z_{s}(0)=0.5$, respectively, for the drive and response systems. The master system parameters are $a=6.8, b=4$, and $c=1$ to ensure the chaotic behavior. 


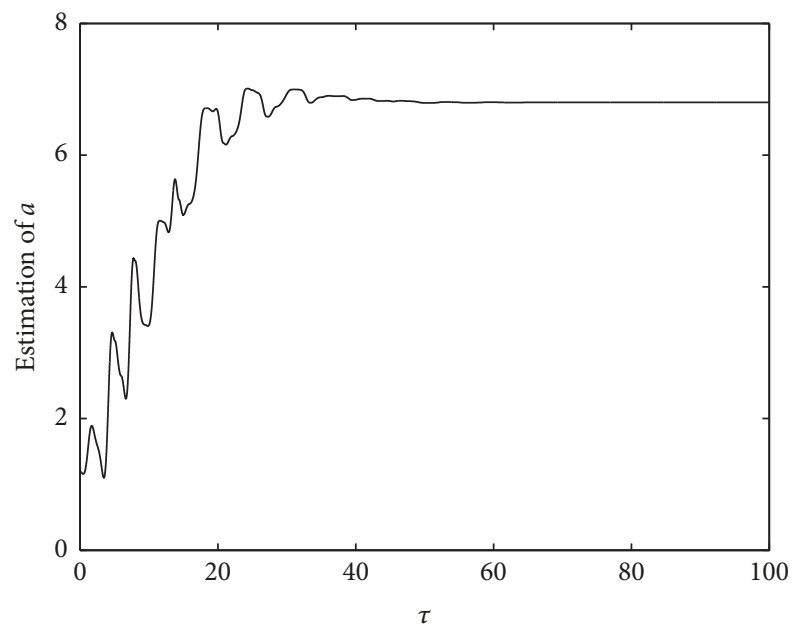

(a)

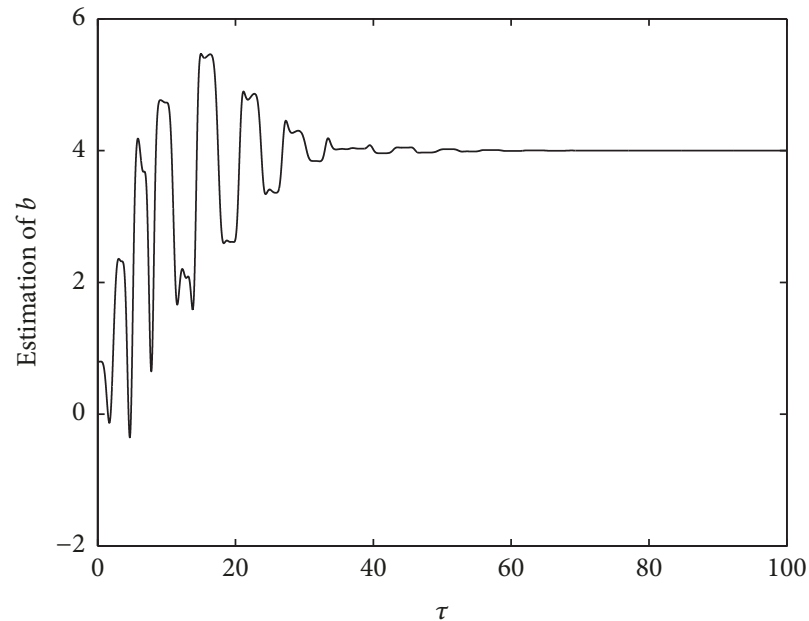

(b)

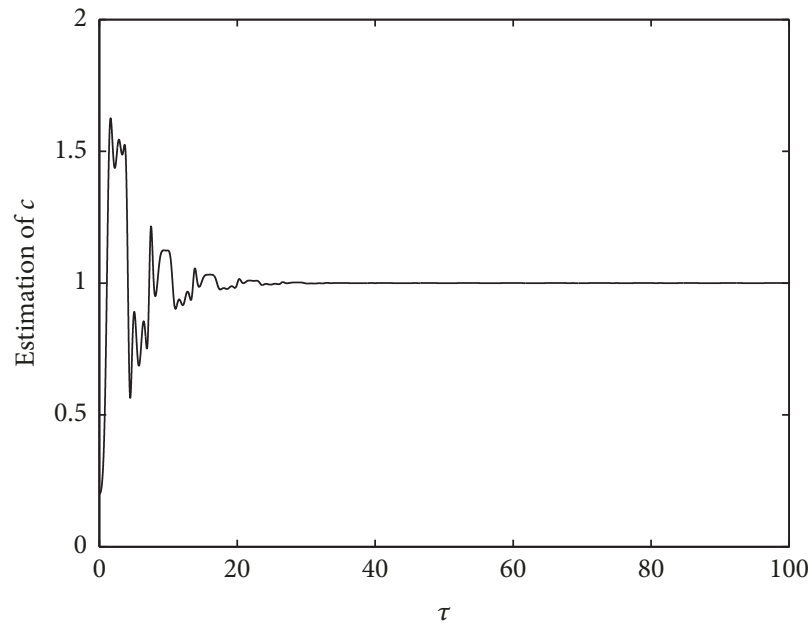

(c)

FIGURE 13: Graphs of estimation of unknown parameters of slave system. (a) $\widehat{a}$, (b) $\hat{b}$, and (c) $\widehat{c}$. The initial conditions are selected randomly as $\widehat{a}(0)=1.2, \widehat{b}(0)=0.8$, and $\widehat{c}(0)=0.25$. 
only one absolute nonlinearity have been investigated. One interesting finding is that the $x$ variable can be adjusted with a control parameter. In addition, it is simple to implement this chaotic system because we do not need any analog multiplier. Adaptive synchronization between such two chaotic systems has been reported and these results should be exploited further for practical applications.

\section{Conflicts of Interest}

The authors declare that there are no conflicts of interest regarding the publication of this paper.

\section{Acknowledgments}

The authors thank Dr. Sifeu Takougang Kingni, Department of Mechanical and Electrical Engineering, Institute of Mines and Petroleum Industries, University of Maroua, for suggesting many helpful references.

\section{References}

[1] E. N. Lorenz, "Deterministic nonperiodic flow," Journal of the Atmospheric Sciences, vol. 20, pp. 130-141, 1963.

[2] O. E. Rössler, "An equation for continuous chaos," Physics Letters A, vol. 57, no. 5, pp. 397-398, 1976.

[3] J. C. Sprott, Elegant Chaos Algebraically Simple Chaotic Flows, World Scientific, Singapore, 2010.

[4] G. Chen and T. Ueta, "Yet another chaotic attractor," International Journal of Bifurcation and Chaos, vol. 9, no. 7, pp. 14651466, 1999.

[5] M. Nategh, D. Baleanu, E. Taghizadeh, and Z. G. Gilani, "Almost local stability in discrete delayed chaotic systems," Nonlinear Dynamics, vol. 89, no. 4, pp. 2393-2402, 2017.

[6] W. Liu, K. Sun, and S. He, "SF-SIMM high-dimensional hyperchaotic map and its performance analysis," Nonlinear Dynamics, vol. 89, no. 4, pp. 2521-2532, 2017.

[7] C. Li, I. Pehlivan, J. Sprott, and A. Akgul, "A novel four-wing strange attractor born in bistability," IEICE Electronics Express, vol. 12, no. 4, pp. 1-12, 2015.

[8] B. C. Bao, Q. Xu, H. Bao, and M. Chen, "Extreme multistability in a memristive circuit," Electronics Letters, vol. 52, pp. 10081010, 2016.

[9] M. Chen, Q. Xu, Y. Lin, and B. Bao, "Multistability induced by two symmetric stable node-foci in modified canonical Chua's circuit," Nonlinear Dynamics, vol. 87, no. 2, pp. 789-802, 2017.

[10] T. Gotthans and J. Petržela, "New class of chaotic systems with circular equilibrium," Nonlinear Dynamics, vol. 73, pp. 429-436, 2015.

[11] T. Gotthans, J. C. Sprott, and J. Petrzela, "Simple Chaotic Flow with Circle and Square Equilibrium," International Journal of Bifurcation and Chaos, vol. 26, no. 8, Article ID 1650137, 2016.

[12] B. Bao, T. Jiang, G. Wang, P. Jin, H. Bao, and M. Chen, “Twomemristor-based Chua's hyperchaotic circuit with plane equilibrium and its extreme multistability," Nonlinear Dynamics, vol. 89, pp. 1157-1171, 2017.

[13] M. P. Aghababa, "Stabilization of a class of fractional-order chaotic systems using a non-smooth control methodology," Nonlinear Dynamics, vol. 89, no. 2, pp. 1357-1370, 2017.
[14] K. Rajagopal, A. Karthikeyan, and A. K. Srinivasan, "FPGA implementation of novel fractional-order chaotic systems with two equilibriums and no equilibrium and its adaptive sliding mode synchronization," Nonlinear Dynamics, vol. 87, no. 4, pp. 2281-2304, 2017.

[15] S. Shao, M. Chen, and X. Yan, "Adaptive sliding mode synchronization for a class of fractional-order chaotic systems with disturbance," Nonlinear Dynamics, vol. 83, no. 4, pp. 1855-1866, 2016.

[16] F. Lin and J. Liu, "Chaotic radar using nonlinear laser dynamics," IEEE Journal of Quantum Electronics, vol. 40, no. 6, pp. 815-820, 2004.

[17] Y. Wang, K.-W. Wong, X. Liao, and G. Chen, "A new chaosbased fast image encryption algorithm," Applied Soft Computing, vol. 11, no. 1, pp. 514-522, 2011.

[18] S. Sadoudi, C. Tanougast, M. S. Azzaz, and A. Dandache, "Design and FPGA implementation of a wireless hyperchaotic communication system for secure real-time image transmission," Eurasip Journal on Image and Video Processing, vol. 2013, article 43, pp. 1-18, 2013.

[19] A. Akgul, H. Calgan, I. Koyuncu, I. Pehlivan, and A. Istanbullu, "Chaos-based engineering applications with a 3D chaotic system without equilibrium points," Nonlinear Dynamics, vol. 84, no. 2, pp. 481-495, 2016.

[20] F. Ozkaynak and S. Yavuz, "Designing chaotic S-boxes based on time-delay chaotic system," Nonlinear Dynamics, vol. 74, no. 3, pp. 551-557, 2013.

[21] S. J. Linz and J. C. Sprott, "Elementary chaotic flow," Physics Letters A, vol. 259, no. 3-4, pp. 240-245, 1999.

[22] J. C. Sprott, "A new class of chaotic circuit," Physics Letters A, vol. 266, no. 1, pp. 19-23, 2000.

[23] J. C. Sprott, "Simple chaotic systems and circuits," American Journal of Physics, vol. 68, no. 8, pp. 758-763, 2000.

[24] P. H. Chang and D. Kim, "Introduction and synchronization of a five-term chaotic system with an absolute-value term," Nonlinear Dynamics, vol. 73, pp. 311-323, 2013.

[25] C. Li, J. C. Sprott, W. Thio, and H. Zhu, "A new piecewise linear hyperchaotic circuit," IEEE Transactions on Circuits and Systems II: Express Briefs, vol. 61, no. 12, pp. 977-981, 2014.

[26] L. Huang and A. Liu, "Analysis and synchronization for a new fractional-order chaotic system with absolute value term," Nonlinear Dynamics, vol. 70, no. 1, pp. 601-608, 2012.

[27] H. Bao, N. Wang, B. Bao, M. Chen, P. Jin, and G. Wang, "Initial condition-dependent dynamics and transient period in memristor-based hypogenetic jerk system with four line equilibria," Communications in Nonlinear Science and Numerical Simulation, vol. 57, pp. 264-275, 2018.

[28] C. Li, J. Wang, and W. Hu, "Absolute term introduced to rebuild the chaotic attractor with constant Lyapunov exponent spectrum," Nonlinear Dynamics, vol. 68, no. 4, pp. 575-587, 2012.

[29] C. Li, J. C. Sprott, Z. Yuan, and H. Li, "Constructing chaotic systems with total amplitude control," International Journal of Bifurcation and Chaos, vol. 25, no. 10, Article ID 1530025, 2015.

[30] C. Li and J. C. Sprott, "Variable-boostable chaotic flows," Optik - International Journal for Light and Electron Optics, vol. 127, no. 22, pp. 10389-10398, 2016.

[31] C. Li, J. C. Sprott, A. Akgul, H. H. C. Iu, and Y. Zhao, "A new chaotic oscillator with free control," Chaos: An Interdisciplinary Journal of Nonlinear Science, vol. 27, no. 8, Article ID 083101, 2017. 
[32] Z. Wei and Q. Yang, "Dynamical analysis of a new autonomous 3-D chaotic system only with stable equilibria," Nonlinear Analysis: Real World Applications, vol. 12, no. 1, pp. 106-118, 2011.

[33] Z. Wei, "Dynamical behaviors of a chaotic system with no equilibria," Physics Letters A, vol. 376, no. 2, pp. 102-108, 2011.

[34] X. Wang and G. Chen, "A chaotic system with only one stable equilibrium," Communications in Nonlinear Science and Numerical Simulation, vol. 17, no. 3, pp. 1264-1272, 2012.

[35] X. Wang and G. Chen, "Constructing a chaotic system with any number of equilibria," Nonlinear Dynamics, vol. 71, no. 3, pp. 429-436, 2013.

[36] S. Bouali, A. Buscarino, L. Fortuna, M. Frasca, and L. V. Gambuzza, "Emulating complex business cycles by using an electronic analogue," Nonlinear Analysis: Real World Applications, vol. 13, no. 6, pp. 2459-2465, 2012.

[37] C. Li, H. Li, and Y. Tong, "Analysis of a novel three-dimensional chaotic system," Optik - International Journal for Light and Electron Optics, vol. 124, no. 13, pp. 1516-1522, 2013.

[38] Q. Lai and L. Wang, "Chaos, bifurcation, coexisting attractors and circuit design of a three-dimensional continuous autonomous system," Optik - International Journal for Light and Electron Optics, vol. 127, no. 13, pp. 5400-5406, 2016.

[39] B. C. Bao, H. Bao, N. Wang, M. Chen, and Q. Xu, "Hidden extreme multistability in memristive hyperchaotic system," Chaos Solitons Fractals, vol. 94, pp. 102-111, 2017.

[40] M. E. Yalcin, J. A. Suykens, and J. Vandewalle, "True random bit generation from a double-scroll attractor," IEEE Transactions on Circuits and Systems I: Regular Papers, vol. 51, no. 7, pp. 13951404, 2004.

[41] C. K. Volos, I. M. Kyprianidis, and I. N. Stouboulos, "A chaotic path planning generator for autonomous mobile robots," Robotics and Autonomous Systems, vol. 60, no. 4, pp. 651-656, 2012.

[42] C. K. Volos, I. M. Kyprianidis, and I. N. Stouboulos, "Image encryption process based on chaotic synchronization phenomena," Signal Processing, vol. 93, no. 5, pp. 1328-1340, 2013.

[43] H. B. Fotsin and P. Woafo, "Adaptive synchronization of a modified and uncertain chaotic van der Pol-Duffing oscillator based on parameter identification," Chaos Solitons Fractals, vol. 24, no. 5, pp. 1363-1371, 2015.

[44] Y. Xu, W. Zhou, J. Fang, and W. Sun, "Adaptive bidirectionally coupled synchronization of chaotic systems with unknown parameters," Nonlinear Dynamics, vol. 66, no. 1-2, pp. 67-76, 2011.

[45] J. Kengne, J. C. Chedjou, G. Kenne, K. Kyamakya, and G. H. Kom, "Analog circuit implementation and synchronization of a system consisting of a van der Pol oscillator linearly coupled to a Duffing oscillator," Nonlinear Dynamics, vol. 70, no. 3, pp. 2163-2173, 2012. 


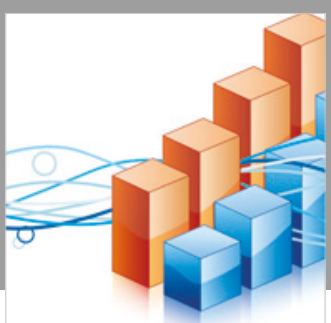

Advances in

Operations Research

\section{-n-m}
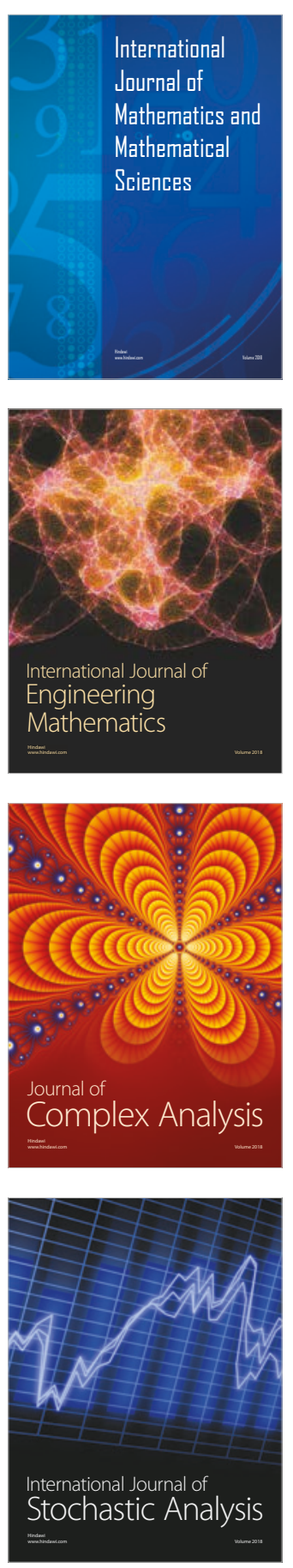
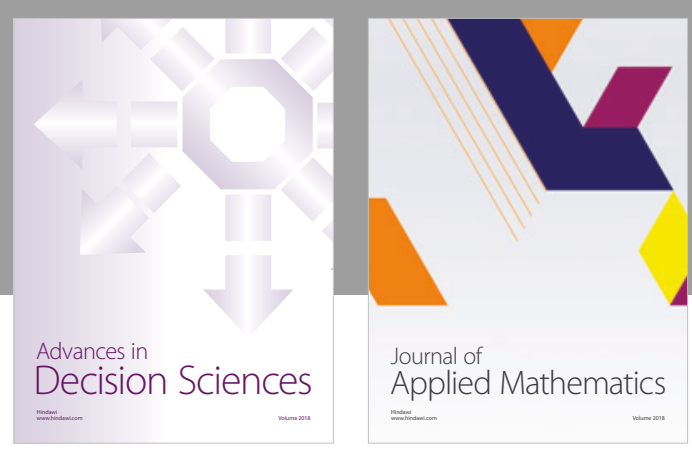

Journal of

Applied Mathematics
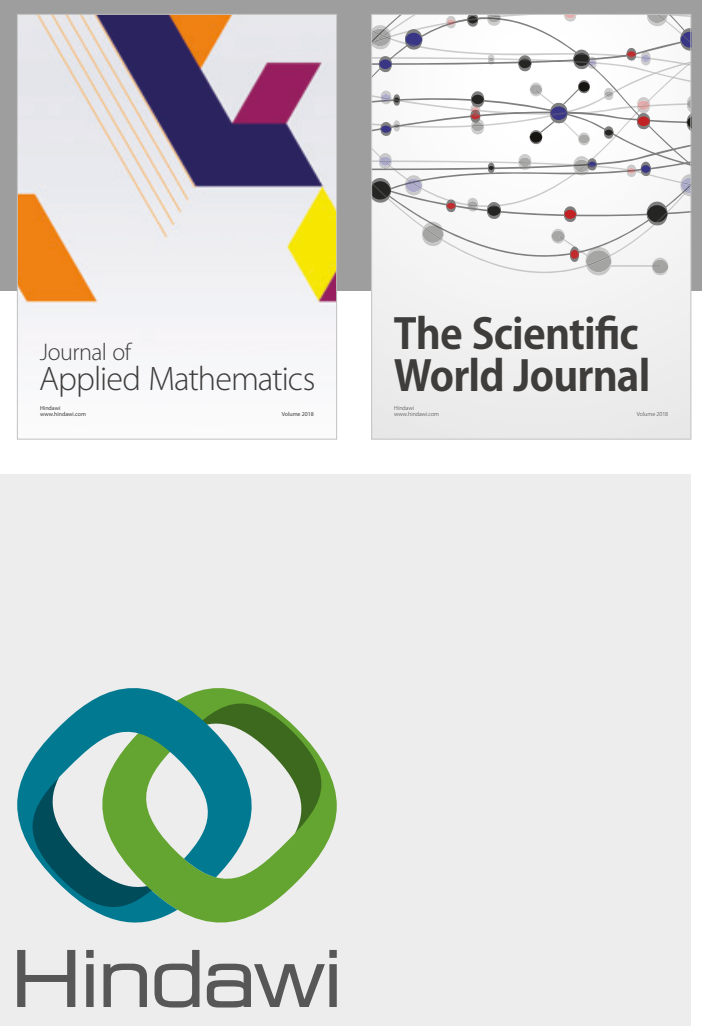

Submit your manuscripts at

www.hindawi.com

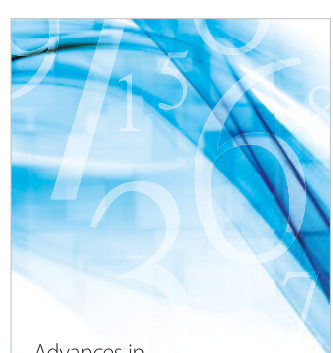

Advances in
Numerical Analysis
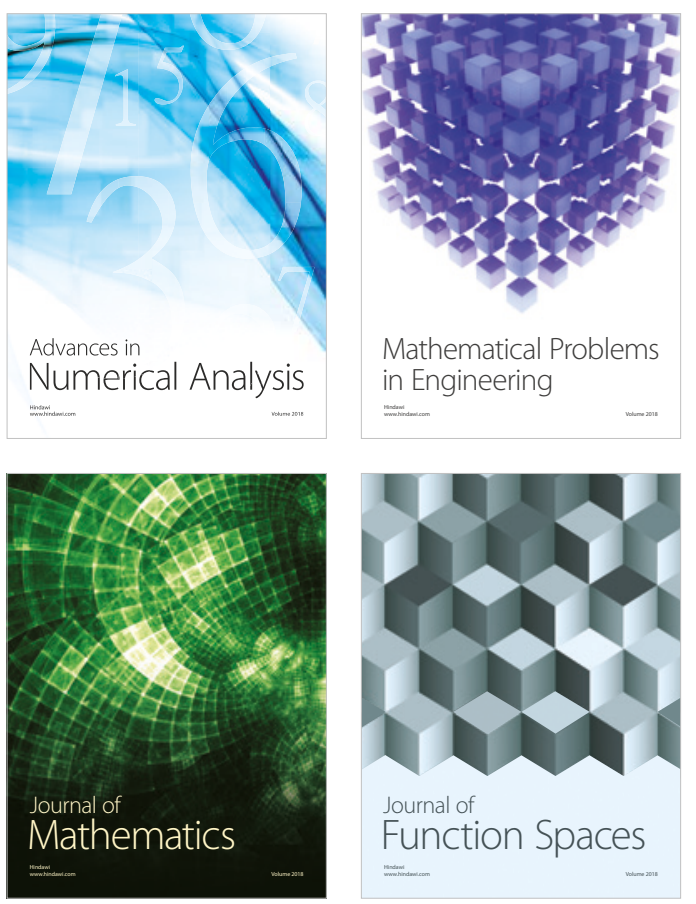

Mathematical Problems in Engineering

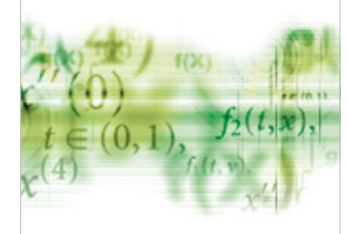

International Journal of

Differential Equations

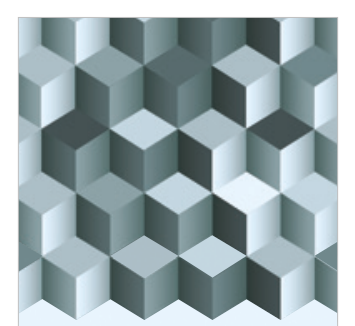

Journal of

Function Spaces

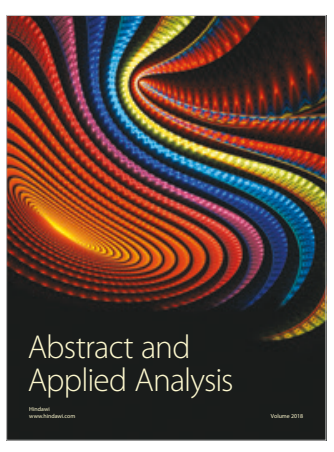

The Scientific

World Journal

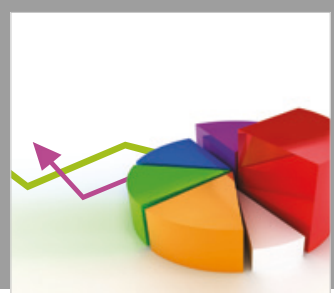

Journal of

Probability and Statistics
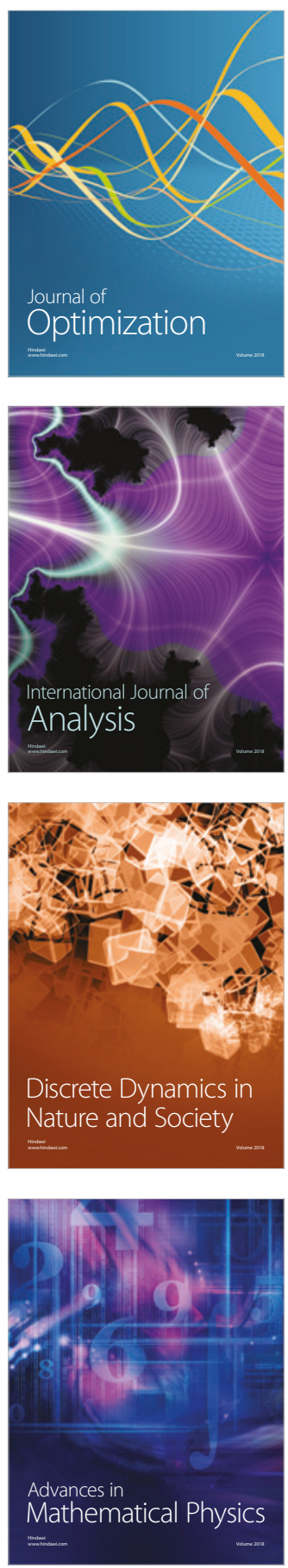